\title{
Spinal Block
}

National Cancer Institute

\section{Source}

National Cancer Institute. Spinal Block. NCI Thesaurus. Code C92887.

A procedure in which a pharmaceutical agent is administered into the subarachnoid space, producing a loss of sensation at and below the level of the block. 